\title{
Efficacy of orally administered oxolinic acid and Vetoquinol, an oxolinic acid ester, for the treatment of furunculosis in Atlantic salmon Salmo salar held in seawater
}

\author{
Ole Bent Samuelsen*, Brit Hjeltnes, Lise Torkildsen
}

Institute of Marine Research, Department of Aquaculture, Strandgaten 229, PO Box 1870, Nordnes, N-5817 Bergen, Norway

\begin{abstract}
This study was performed to determine the efficacy of orally administered oxolinic acid and Vetoquinol, an oxolinic acid ester, in the treatment of experimental induced furunculosis in Atlantic salmon Salmo salar held in seawater. Two strains of the causative bacterium Aeromonas salmonicida subsp. salmonicida, 1 sensitive (VI-88/09/03175) and 1 resistant (3475/90) to oxolinic acid, were used. In 2 trials, cohabitational challenges were performed by introducing 8 fish challenged in advance by an intraperitoneal injection of $2.2 \times 10^{4}$ colony forming units of strain $3475 / 90$ (Trial 1 ) or strain VI-88/09/03175 (Trial 2) to 10 aquaria each containing 40 healthy fish. The treatment groups in both trials consisted of 4 groups receiving either oxolinic acid ( 2 groups) or Vetoquinol ( 2 groups) and 1 control group. An unchallenged, unmedicated group was used to determine the natural mortality in the population. The recommended therapeutic dose of $25 \mathrm{mg}$ oxolinic acid $\mathrm{kg}^{-1}$ fish at Days $1,2,4,6,8$ and 10 following initiation of treatment was used. Oral medication initiated at Day 10 (Trial 1) or Day 11 (Trial 2) following challenge significantly $(\mathrm{p}<0.05)$ lowered the specific mortality in all drug-treated groups compared to the untreated control groups. Mortality in Vetoquinol-treated groups was significantly $(\mathrm{p}<0.05)$ lower than in oxolinic acid-treated groups in Trial 1 whereas no significant $(p<0.05)$ difference in survival rate was found between the medicated groups in Trial 2.
\end{abstract}

KEY WORDS: Efficacy · Furunculosis - Oxolinic acid · Vetoquinol · Atlantic salmon

\section{INTRODUCTION}

Vaccination and improved management practices have reduced the problem with bacterial diseases in the culture of Atlantic salmon Salmo salar in Norway. However, when outbreaks occur, antimicrobial therapy is essential to treat the infection. The quinolones flumequine and oxolinic acid have been shown to be effective against a number of bacterial infections in fish (Michel et al. 1980, Austin et al. 1983, Rodgers \& Austin 1983, Scallan \& Smith 1985, O'Grady et al. 1988) and have since their introduction in 1987 (oxolinic acid) and 1989 (flumequine) been the drugs of choice in Norwegian aquaculture (Grave et al. 1996). Quinolones are broad-spectrum synthetic antibacterial

\footnotetext{
- Present address: Department of Pharmacology, Armauer Hansens Hus, N-5021 Bergen, Norway.

E-mail: ole.samuelsen@farm.uib.no
}

agents especially active against Gram-negative bacteria. The antibacterial activity is based on the inhibition of DNA-gyrase, resulting in an unstable condensation of the DNA configuration of the bacterial DNA molecule during cell division (Wolfson \& Hooper 1989).

Extensive use of an antibacterial agent may cause the emergence of bacterial strains resistant to a drug and thereby decrease the efficacy of treatment. Tsoumas et al. (1989) suggested that a bacterium should be considered susceptible to oxolinic acid if the in vitro minimum inhibitory concentration (MIC) is $<0.0625 \mathrm{\mu g} \mathrm{ml}^{-1}$ and moderately susceptible when the $\mathrm{MIC}$ is within the range of 0.125 to $0.5 \mu \mathrm{g} \mathrm{ml}^{-1}$. With an MIC of $\geq 1.0 \mu \mathrm{g} \mathrm{ml}^{-1}$ a strain should be classified as resistant. Barnes et al. (1990) found the in vitro MIC values for oxolinic acid against 45 susceptible strains of Aeromonas salmonicida to range from 0.05 to $0.7 \mu \mathrm{g}$ $\mathrm{ml}^{-1}$ and from 1 to $15 \mathrm{\mu g} \mathrm{ml}^{-1}$ for 38 resistant strains. Of 44 tested strains of Aeromonas salmonicida subsp. 
salmonicida, Martinsen et al. (1992) found 22 strains to be oxolinic acid sensitive and 22 strains to be oxolinic acid resistant, applying the criteria proposed by Tsoumas et al. (1989).

A theoretical assessment of the clinical significance of an antibacterial agent towards a specific pathogen is based upon pharmacokinetic parameters of the drug and the pathogen's MIC value for that particular antibacterial. Stamm (1989) has suggested that a peak plasma concentration $\left(C_{\max }\right)$ :MIC ratio of $4: 1$ would be sufficient to inhibit bacterial growth whereas Blaser et al. (1987), following in vitro studies with the quinolone enoxacin, suggested that bacterial regrowth might occur unless the ratio achieved was $8: 1$. Furthermore Smith et al. (1994) have argued that any theoretical considerations of this issue are complicated by the fact that the majority of plasma concentration data has been generated by chemical analytical methods like high-performance liquid chromatography (HPLC) and therefore, may not express the actual in vivo biological activity of the drug. Peak plasma concentrations ranging from 0.5 to $0.99 \mu \mathrm{g} \mathrm{ml}^{-1}$ are reported for oxolinic acid following oral administration of medicated feed at a dosage of $25 \mathrm{mg} \mathrm{kg}^{-1}$ body weight to Atlantic salmon held in seawater (Martinsen 1993, Rogstad et al. 1993 Martinsen \& Horsberg 1995). Unpublished data by Samuelsen (Institute of Marine Research, Bergen, Norway) showed that oral administration of oxolinic acid as the carbitol-ester (Vetoquinol) to Atlantic salmon held in seawater enhanced important pharmacokinetic properties such as bioavailability, $C_{\max }$ and $T_{\max }$ (time to reach $C_{\max }$ ) compared to administration of an equal dose of oxolinic acid. A major part of the ester was rapidly converted in vivo to oxolinic acid, and the peak plasma concentration of oxolinic acid increased from $0.5 \mu \mathrm{g} \mathrm{ml}^{-1}$ when oxolinic acid was administered to 3.8 $\mu \mathrm{g} \mathrm{ml} \mathrm{m}^{-1}$ when Vetoquinol was administered whereas $T_{\max }$ decreased from 19 to $7 \mathrm{~h}$. The gain in pharmacokinetic properties may improve the efficacy of the drug and this study was designed to examine the efficacy of orally administrated Vetoquinol and oxolinic acid in the treatment of furunculosis in Atlantic salmon held in seawater using a cohabitant challenge model. Two different strains of the pathogen were used, 1 sensitive (VI-88/09/03175) and 1 resistant $(3475 / 90)$ to oxolinic acid, following the criteria proposed by Tsoumas et al. (1989).

\section{MATERIALS AND METHODS}

Chemicals. Flumequine, oxolinic acid and metomidate were from Norsk Medisinaldepot (Bergen, Norway). Vetoquinol, the carbitol ester of oxolinic acid was kindly supplied by Prof. Loubinoux (Universite de
Nancy, France). Methanol, acetonitrile, tetrahydrofuran (HPLC-grade) and oxalic acid dihydrate, TRIS and HCl (p.a.-grade) were all from Merck (Darmstadt, Germany).

Stock solutions of flumequine, oxolinic acid and Vetoquinol were prepared at a concentration of $0.1 \mathrm{mg}$ $\mathrm{ml}^{-1}$ in acetonitrile and stored at $-20^{\circ} \mathrm{C}$. Acetonitrile was used due to de-esterification of Vetoquinol when stored in methanol or diluted alkali $(0.025 \mathrm{M} \mathrm{NaOH})$. Working standards were prepared by dilution from the stock solutions with acetonitrile.

MIC determinations. Determination of MIC values was performed using the agar dilution method (Washington 1985, Samuelsen \& Lunestad 1996) with some modifications. Strains were maintained on Mueller Hinton agar (Difco) supplemented with $2 \% \mathrm{NaCl}$. Material from the strains were transferred to $10 \mathrm{ml}$ Mueller Hinton broth and incubated for $48 \mathrm{~h}$ at $20^{\circ} \mathrm{C}$ giving a final cell density of approximately $5 \times 10^{8}$ cells $\mathrm{ml}^{-1}$. Using a $10 \mu \mathrm{l}$ inoculation loop, bacteria from this broth were distributed on the surface of Mueller Hinton Agar supplemented with $2 \% \mathrm{NaCl}$ and containing oxolinic acid. The antibacterial agent was added to the agar in 2-fold dilutions from a newly prepared stock solution. The temperature of the agar on addition of the agent was $50^{\circ} \mathrm{C}$. Following incubation at $20^{\circ} \mathrm{C}$ for $72 \mathrm{~h}$ the plates were examined for bacterial growth. The lowest concentration of oxolinic acid at which complete inhibition occurred was recorded as the MIC. MIC testing was performed in triplicate.

Feed. Both medicated and non-medicated feeds for oral administrations were made at the Institute of Nutrition, Directorate of Fisheries (Bergen, Norway). The ingredients were squid $(9.2 \%)$, wheat meal $(17 \%)$ herring meal (57\%), vitamins and minerals (1.8\%), gelatin $(3 \%)$ and herring oil $(12 \%)$. The medicated feeds were made by homogeneously mixing $5 \mathrm{~g}$ oxolinic acid or $7.2 \mathrm{~g}$ Vetoquinol, corresponding to $19.2 \mathrm{mmol}$ for both compounds, with $1 \mathrm{~kg}$ fish feed ingredients

Experimental fish. Non-vaccinated Atlantic salmon with a mean weight of $65 \pm 9 \mathrm{~g}$ were maintained in a circular (1 $\mathrm{m} \times 2.5 \mathrm{~m}$ inside diameter) flow-through seawater storage-tank at the laboratory of the Institute of Marine Research, Bergen, Norway. The seawater had a salinity of $33 \%$ and a temperature of $11.5 \pm$ $0.5^{\circ} \mathrm{C}$. The fish were fed a non-medicated ration of $1 \%$ body weight $\mathrm{d}^{-1}$ of dry pellets.

Challenge. Aeromonas salmonicida subsp. salmonicida strain VI-88/09/03175 (Culture collection, Central Veterinary Laboratory, Oslo, Norway) and strain 3475/90 (Norwegian College of Veterinary Medicine, Oslo, Norway) were used for the challenge experiments. These strains are pathogenic to Atlantic salmon. With MIC values of 0.13 and $4 \mu \mathrm{g} \mathrm{ml}^{-1}$, respec- 
tively, strain VI-88/09/03175 is classified as moderately susceptible and strain $3475 / 90$ as resistant to oxolinic acid (Tsoumas et al. 1989). The bacteria were stored in cryotubes with glycerol at $-80^{\circ} \mathrm{C}$. Prior to challenge, the bacteria were inoculated into brain heart infusion broth (BHIB) from Merck and incubated at $20^{\circ} \mathrm{C}$. After $24 \mathrm{~h}, 1 \%$ of this culture was inoculated into a new culture and incubated for $24 \mathrm{~h}$. The bacteria were harvested by centrifugation at $4000 \mathrm{rpm}(2750 \times g)$ and $4^{\circ} \mathrm{C}$ for 10 min and washed twice with $0.85 \%$ sterile $\mathrm{NaCl}$. The pellet was resuspended to $40 \%$ transmission reading and diluted to $10^{-3}$ in $0.85 \%$ sterile $\mathrm{NaCl}$ prior to the injection. The number of colony-forming units (CFUs) was determined by plate counts.

Fish from the storage tank were randomly assigned to 10 groups, each of 40 fish and transferred to $10 \mathrm{cir}$ cular $(0.8 \mathrm{~m} \times 1 \mathrm{~m}$ inside diameter) flow-through seawater tanks maintained at $11.5 \pm 0.5^{\circ} \mathrm{C}$. The fish were acclimatised for $2 \mathrm{wk}$. At the end of the acclimatisation period the fish consumed the apportioned amount of unmedicated feed of $1 \%$ body weight $\mathrm{d}^{-1}$

Trial 1: A cohabitation challenge was performed by transferring 8 challenged fish to each of 5 tanks containing 40 healthy fish. Prior to the transfer the cohabitant fish were anaesthetised by immersion in a solution of metomidate $\left(5 \mathrm{mg} \mathrm{l}^{-1}\right)$ in seawater for approximately $5 \mathrm{~min}$, marked by fin clipping and challenged by an intraperitoneal injection of $2.2 \times 10^{4} \mathrm{CFU}$ of the bacterial strain $3475 / 90$. This corresponded to a challenge pressure of $20 \%$ (\% cohabitant fish to noncohabitants). Treatment with oxolinic acid (Groups 1 and 2) and Vetoquinol (Groups 3 and 4) was initiated at Day 10 postchallenge with medication at Days 1, 2, 4, 6,8 and 10 following initiation of treatment. The fish in Group 5 received no medication and served as controls

Trial 2: In Trial 2, 8 cohabitant fish were anaesthetised using metomidate, marked by fin clipping and challenged by an intraperitoneal injection of $2.2 \times 10^{4}$ $\mathrm{CFU}$ of the bacterial strain VI-88/09/03175 prior to transfer to each of the 5 remaining tanks. Treatment with oxolinic acid (Groups 6 and 7 ) and Vetoquinol (Groups 8 and 9) was initiated at Day 11 postchallenge with medication at Days $1,2,4,6,8$ and 10 following initiation of treatment. The fish in Group 10 received no medication and served as controls.

On the day of challenge the seawater temperature in all tanks was raised from 11.5 to $14^{\circ} \mathrm{C}$ and kept at $14 \pm$ $0.5^{\circ} \mathrm{C}$ for the rest of the experiment. The water flow was $4 \mathrm{l} \mathrm{min} \mathrm{m}^{-1}$ and the oxygen concentration was $8.0 \mathrm{mg}$ $\mathrm{I}^{-1}$.

Treatment. The medicated feeds contained oxolinic acid and Vetoquinol at a concentration of 5 and $7.2 \mathrm{~g}$, respectively, $\mathrm{kg}^{-1}$ feed, designed to deliver a dosage of $25 \mathrm{mg}$ oxolinic acid $\mathrm{kg}^{-1}$ body weight $\mathrm{d}^{-1}$ based on administration of a daily feed ration of $0.5 \%$ fish body weight. During medication the fish in the control groups were fed a ration of unmedicated feed of $0.5 \%$ fish body weight $d^{-1}$. The fish were fed once a day and approximately $1 \mathrm{~h}$ after feeding excess food was collected from each tank and the percentage of medicated feed consumed each day estimated. The amount of feed administered each day was readjusted to account for fish that had died in the tanks during the last $24 \mathrm{~h}$. In the post medication period, the feed and feeding regime was as described for the acclimatisation period. The fish in both trials were observed for $24 \mathrm{~d}$ postchallenge and mortality was recorded daily. Dead fish were removed from the tanks once a day and examined for food residues in the stomach and gut. Samples of muscle were obtained from the dead fish and stored at $-20^{\circ} \mathrm{C}$ until analysed for oxolinic acid and Vetoquinol residues. Kidney samples from the dead fish and 5 surviving fish from each group were inoculated on brain heart broth (BHB) (Merck) and incubated aerobically at $20^{\circ} \mathrm{C}$ for $4 \mathrm{~d}$. The Aeromonas salmonicida subsp. salmonicida strains were identified according to morphology, production of brown pigment, positive agglutination test (Mono-Va, BioNor Aqua, Skien, Norway) and biochemical characteristics in API $20 \mathrm{E}$ (bio Mérieux, Marcy l'Etoile, France). An additional group of 100 unchallenged fish was used to determine the natural mortality in the population. Treatments were compared on the basis of cumulative mortality at the end of the study using the mean value of parallel treated groups and the chi-square test.

Sample preparation. Samples of muscle (1 g) were homogenised in $1.0 \mathrm{ml}$ of a $50: 50 \%$ solution of acetonitrile and $0.05 \mathrm{M}$ Tris: $\mathrm{HCl}$ buffer ( $\mathrm{pH} \mathrm{8.0)}$ containing flumequine as internal standard. Following homogenisation, $0.5 \mathrm{ml}$ of the homogenate was transferred to a polypropylene tube and kept in the dark at $4^{\circ} \mathrm{C}$ for $24 \mathrm{~h}$ for complete precipitation of proteins. Flumequine, oxolinic acid and Vetoquinol were all found to be stable for $24 \mathrm{~h}$ in the solution of acetonitrile and Tris: $\mathrm{HCl}$ buffer. After centrifugation at $12000 \times g$ in a Biofuge $\mathrm{A}$ table-centrifuge (Heraeus Sepatech, Osterode am Harz, Germany) for 5 min, a clear supernatant was obtained, ready for analysis.

Chromatography. The HPLC system used consisted of a Spectra-Physics SP 8800 ternary HPLC pump (Spectra-Physics, San Jose, CA, USA) connected to a Spectra-Physics SP 8780 X R Autosampler and a Shimadzu RF-535 fluorescence detector (Shimadzu, Kyoto, Japan) operating at an excitation wavelength of $325 \mathrm{~nm}$ and an emission wavelength of $360 \mathrm{~nm}$. The integrator was the model SP-4270 from SpectraPhysics. The HPLC system was programmed to inject $20 \mu \mathrm{l}$ samples into the $150 \times 4.6 \mathrm{~mm}$ analytical column packed with $3 \mu \mathrm{m}$ particles of ODS-Hypersil (C-18) 
(Shandon Southern Products, Astmoor, UK) in our laboratory using a Shandon column packing machine. The column was operated at room temperature. The mobile phase used contained A: $0.025 \mathrm{M}$ oxalic acid pH 3.2 - acetonitrile - methanol - tetrahydrofuran (70 $7.5-20-2.5 \mathrm{v} / \mathrm{v}$ ); and $\mathrm{B}: 0.025 \mathrm{M}$ oxalic acid $\mathrm{pH} 3.2$ acetonitrile - methanol - tetrahydrofuran (50 - 20 - 25 $5 \mathrm{v} / \mathrm{v}$ ). The solutions were filtered through a $0.2 \mu \mathrm{m}$ Millipore filter. The elution profile was as follows: 0 to $4 \mathrm{~min}$ isocratic $100 \% \mathrm{~A}_{;} 4.1$ to $10 \mathrm{~min} 0$ to $100 \% \mathrm{~B}$ linear gradient; 10.1 to $15 \mathrm{~min}$ isocratic $100 \% \mathrm{~B}_{;} 15.1$ to $20 \mathrm{~min}$ isocratic $100 \% \mathrm{~A}$. The flow rate was $1 \mathrm{ml} \mathrm{min}^{-1}$, giving elution times of $8.6 \mathrm{~min}$ (oxolinic acid), $9.3 \mathrm{~min}$ (Vetoquinol) and $12.8 \mathrm{~min}$ (flumequine).

Muscle samples from 3 fish were taken prior to initiation of the study and analysed to confirm the absence of flumequine, oxolinic acid and Vetoquinol. Standard curves for oxolinic acid and Vetoquinol in muscle in the range of 0.01 to $1.0 \mathrm{\mu g} \mathrm{g}^{-1}$, using an internal standard concentration of $1.0 \mathrm{\mu g} \mathrm{g}^{-1}$ and 1.0 to $10.0 \mu \mathrm{g} \mathrm{g}^{-1}$ (internal standard of $5.0 \mu \mathrm{g} \mathrm{g}^{-1}$ ), were prepared in triplicate. Based on the standard curves, the limits of quantitation in this investigation were set to $0.025 \mu \mathrm{g}$ $\mathrm{g}^{-1}$ for oxolinic acid and $0.1 \mu \mathrm{g} \mathrm{g}^{-1}$ for Vetoquinol in muscle samples.

\section{RESULTS}

Trial 1: Within $7 \mathrm{~d}$ after challenge the majority of the fish challenged with an intraperitoneal injection of the pathogen were dead whereas the first deaths of semichallenged fish occurred at Day 10 following challenge. Among challenged controls (Group 5) the cumulative mortality reached $92 \%$ during the postchallenge period of $24 \mathrm{~d}$. For fish medicated with oxolinic acid the final cumulative mortality was $76 \%$ whereas for fish medicated with Vetoquinol a final cumulative mortality of $60 \%$ was found. Cumulative mortalities over time are presented for the medicated groups as the mean value of the 2 groups with parallel treatment (Fig. 1). No mortality was observed in the unchallenged, unmedicated group. Survival of fish medicated with oxolinic acid and Vetoquinol were significantly ( $p<0.05$ and $p<0.005$, respectively) greater than survival of challenged unmedicated fish. The mortality of Vetoquinol-treated fish was significantly lower $(p<0.05)$ than fish treated with oxolinic acid. A comparison of mortality in groups with an identical treatment regime demonstrated no significant difference between the groups ( $p>0.05$ ). The relative per cent survival (RPS) (Inglis et al. 1991) was calculated to be 18 and $35 \%$ respectively when treated with oxolinic acid or Vetoquinol. The mortality ceased within $8 \mathrm{~d}$ in all medicated groups after initiation of treatment.

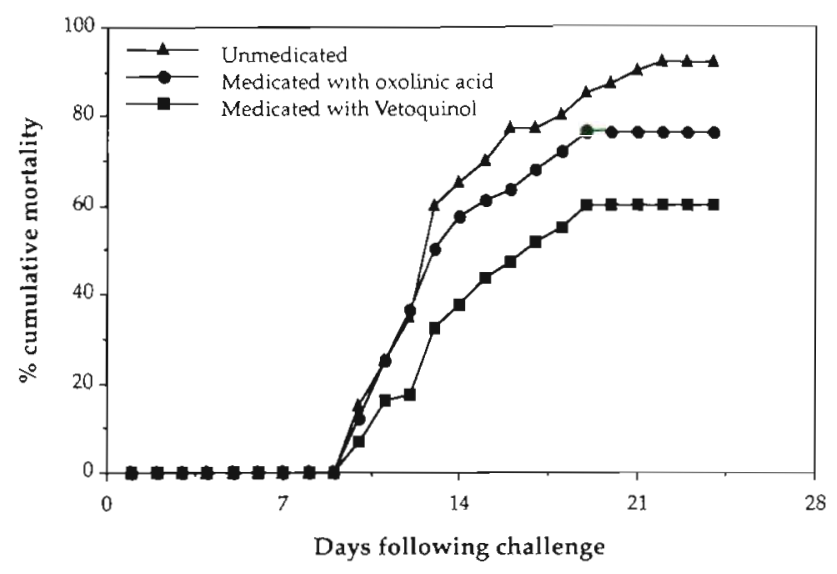

Fig. 1. Salmo salar. Cumulative mortalities over time of medicated and nonmedicated groups challenged with an oxolinic acid resistant strain of Aeromonas salmonicida subsp. salmonicida (MIC value of $4 \mu \mathrm{g} \mathrm{ml}^{-1}$ ) in Trial 1. Data is presented as mean values of parallel tanks applying original mortality data. Oral medication was initiated at Day 10 following challenge

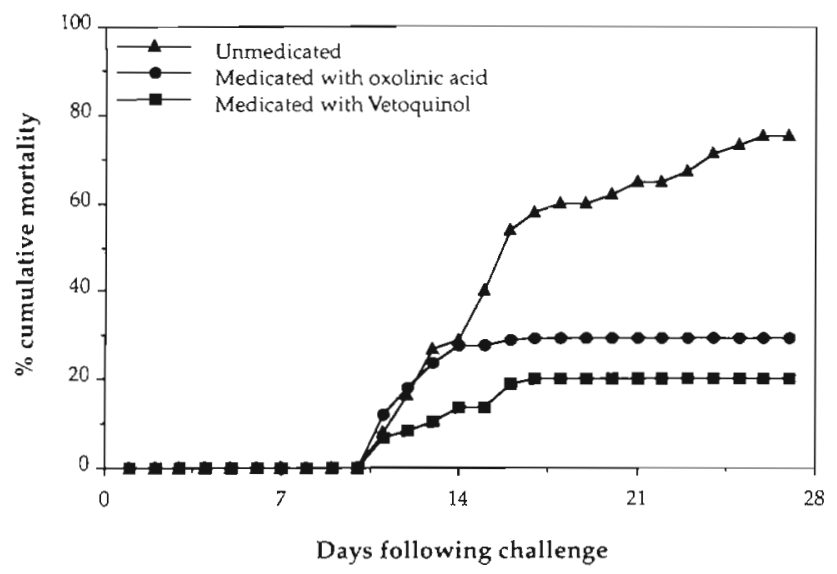

Fig. 2. Salmo salar. Cumulative mortalities over time of medicated and nonmedicated groups challenged with a sensitive strain of Aeromonas salmonicida subsp. salmonicida (MIC value of $0.13 \mu \mathrm{g} \mathrm{ml}^{-1}$ ) in Trial 2. Data is presented as mean values of parallel tanks applying original mortality data. Oral medication was initiated at Day 11 following challenge

Trial 2: When the first deaths of semi-challenged fish occurred in Trial 2 at Day 11 following challenge, half of the fish challenged with an intraperitoneal injection. were dead. Among challenged controls (Group 10) the mortality reached $75 \%$ during the postchallenge period of 24 d. For fish medicated with oxolinic acid a final cumulative mortality of $29.5 \%$ was found whereas the corresponding value for fish medicated with Vetoquinol was $20 \%$. Cumulative mortalities over time (mean value of parallel treated groups) are shown in Fig. 2. Survival of fish in all medicated groups were significantly $(p<0.005)$ greater than survival of challenged 
unmedicated fish. No significant $(p<0.05)$ difference in survival rate was found between the groups medicated with oxolinic acid or Vetoquinol. However, a significant difference $(p<0.05)$ was found between Groups 6 and 7 , medicated with oxolinic acid in a parallel treatment. In this trial the RPS values were calculated to be 61 and $73 \%$, respectively, when treated with oxolinic acid or Vetoquinol. The mortality ceased within $4 \mathrm{~d}$ in all medicated groups after initiation of treatment.

Aeromonas salmonicida subsp. salmonicida was isolated from the kidneys from all examined dead fish from both trials whereas the pathogen was not isolated from the survivors of either of the medicated groups.

In all tanks throughout the experiment, $100 \%$ of the ration of medicated feed was consumed. The dead fish, classified as low-feeders, had no or very little feed in the stomach or intestine. This observation was confirmed by the HPLC analysis showing low concentrations $\left(<0.8 \mu \mathrm{g} \mathrm{g}^{-1}\right)$ of oxolinic acid in muscle of the dead fish. In comparison the mean concentration of oxolinic acid in muscle of surviving fish from Trial 2 was $2.85 \mu \mathrm{g}$ $\mathrm{g}^{-1} 5 \mathrm{~d}$ following the termination of medication.

\section{DISCUSSION}

The culture and presumptive identification of Aeromonas salmonicida subsp. salmonicida from the dead fish from both trials was expected and validates the pathogen as the probable cause of death. None of the surviving medicated fish cultured positive for $A$. salmonicida subsp. salmonicida, indicating that the pathogen was effectively removed from the fish by the antibacterials.

In this investigation the MICs for oxolinic acid against the bacterial strains were $0.13 \mu \mathrm{g} \mathrm{ml}^{-1}$ for strain VI-88/09/03175 and $4 \mu \mathrm{g} \mathrm{ml}^{-1}$ for strain $3475 / 90$. These results are in accordance with the results of Oppegaard \& Srrum (1994), who found the MIC value for strain $3475 / 90$ to be $2.56 \mu \mathrm{g} \mathrm{ml}^{-1}$.

Although oxolinic acid has been used to treat furunculosis in Atlantic salmon for years, surprisingly few data on the in vivo efficacy of this antibacterial agent against infection with Aeromonas salmonicida are available. In this investigation we found the cumulative mortality in the groups medicated with oxolinic acid or Vetoquinol in both trials to be significantly $(p<$ 0.05 and $p<0.005$ ) lower compared to unmedicated groups. The efficacy of a medical treatment can be expressed by calculation of the RPS value. This calculation allows the effect of treatment to be measured against the severity of challenge. In the present study a total dose of $150 \mathrm{mg}$ orally administered oxolinic acid $\mathrm{kg}^{-1}$ body weight gave a RPS value of $18 \%$ in Trial 1 and $61 \%$ in Trial 2 whereas oral administration of
Vetoquinol gave RPS values of 35 and $73 \%$, respectively. For Trial 2 our findings are similar to previously published results. From data presented by Nordmo et al. (1998) a RPS value of $56.4 \%$ could be calculated for oxolinic acid in treating furunculosis-infected Atlantic salmon with a daily dose of $25 \mathrm{mg} \mathrm{kg}^{-1}$ fish $\mathrm{d}^{-1}$ for $10 \mathrm{~d}$. Daily medication with flumequine $\left(25 \mathrm{mg} \mathrm{kg}^{-1}\right)$, oxytetracycline $\left(100 \mathrm{mg} \mathrm{kg}^{-1}\right)$, trimethoprim + sulphadiazine $\left(5+25 \mathrm{mg} \mathrm{kg}^{-1}\right)$ and florfenicol $\left(10 \mathrm{mg} \mathrm{kg}^{-1}\right)$ for $10 \mathrm{suc}-$ cessive days gave RPS values of $64,66,56$ and $70 \%$, respectively (Nordmo et al. 1998). Initiating medication at Days 10, 13 and 16 following a cohabitational challenge of Atlantic salmon held in seawater with $A$. salmonicida subsp. salmonicida, daily doses of florfeni$\mathrm{Col}\left(10 \mathrm{mg} \mathrm{kg}^{-1}\right.$ ) for $10 \mathrm{~d}$ gave RPS values of 96,84 and $76 \%$, respectively (Samuelsen et al. 1997), whereas Inglis et al. (1991) found a RPS value of $82 \%$ when treating furunculosis-infected Atlantic salmon parr with florfenicol. Field trials for the treatment of furunculosis-infected rainbow trout with oxolinic acid yielded $99 \%$ survival in the treated group versus $69 \%$ survival in the unmedicated group giving a RPS value of $97 \%$ (Austin et al. 1983). It must be noted, however, that due to variables in experimental set-up and test systems between the different investigations comparisons of RPS values must be made with caution.

Statistical treatment of our data suggest that medication with Vetoquinol was superior to medication with oxolinic acid in Trial 1 and that, although a trend in increasing efficacy using Vetoquinol compared to oxolinic acid was observed in Trial 2, the difference between the groups was not large enough to be statistically significant, at least at the sample size employed in this study. It is of interest that even though an oxolinic acid-resistant strain was used in Trial 1, treatment with oxolinic acid gives at least some protection against the pathogen since the final cumulative mortality using oxolinic acid was found to be significantly $(\mathrm{p}<0.05)$ lower compared with the control group. It must be kept in mind, however, that oxolinic acid resistant isolates of Aeromonas salmonicida with MIC values much higher than $4 \mu \mathrm{g} \mathrm{ml}^{-1}$ are described in the literature and that medication even with Vetoquinol most probably would be inappropriate for the treatment of such isolates (Barnes et al. 1990, Martinsen et al. 1992). Figs. 1 \& 2 show that the major difference in mortality rate between the 2 drugs is in the first $3 \mathrm{~d}$ following initiation of treatment where the mortality is nearly twice as large in the oxolinic acid-treated groups compared to the Vetoquinol groups. This observation is supported by unpublished data of Samuelsen, who found that important pharmacokinetic parameters such as bioavailability, $C_{\max }$ and $T_{\max }$ were largely improved when Vetoquinol was administered as compared to oxolinic acid. Our data 
validate the importance of obtaining a high concentration of the antibacterial in the fish as quickly as possible and suggest that the efficacy of a high loading dose of the antibacterial agent at Day 1 of medication should be investigated.

To test the efficacy of chemotherapeutants, different challenge models have been used to experimentally induce furunculosis in fish (Elston et al. 1995, Samuelsen et al. 1997, Nordmo et al. 1998). To mimic natural infection the disease was induced in this investigation by introduction of cohabitant fish previously infected by an intraperitoneal injection with the pathogen. However, as previously shown by Nordmo et al. (1998), it is more difficult to achieve an identical challenge environment in all tanks in a cohabitant challenge model compared to intraperitoneal inoculation. In Trial 2 in this study we found a significant $(p<$ $0.05)$ difference in final cumulative mortality between the 2 parallel tanks treated with oxolinic acid (Groups 6 and 7). However, in Group 7 the premedication mortality among the semi-challenged fish was higher than in the other groups. If this effect was adjusted for by reducing the number of fish in Group 7 to a premedication mortality corresponding to the mean value of the 4 remaining groups, no significant $(p<0.05)$ difference was then found between Groups 6 and 7 . It should be noted that the figures and the statistical calculations presented in this investigation were based upon the original data. However, the results of the statistical calculations were not altered if the adjusted data were used.

The feeding observations made in these trails verified that all the medicated feed was consumed by the fish. However, the dead fish had no or very little feed in the intestine and were classified as low-feeders. This observation was confirmed by the HPLC analysis showing the absence or low concentrations $k 0.8 \mu \mathrm{g}$ $\mathrm{g}^{-1}$ ) of oxolinic acid in muscle of the dead fish. In comparison, the mean concentration of oxolinic acid in muscle of 20 surviving fish from Trial 2 were $2.85 \mu \mathrm{g}$ $\mathrm{g}^{-1}, 5 \mathrm{~d}$ following terminated medication. We therefore believe that most of the fish not consuming the full dose may have been the individuals succumbing to the disease.

These studies indicate that the value of Vetoquinol in treating furunculosis in Atlantic salmon held in seawater lies in its better effect on bacterial strains classified as resistant, as shown in Trial 1, and the quicker response (i.e. lower mortality rate) in the first days of treatment compared to oxolinic acid, as shown in both trials in this investigation.

Acknowledgements. This work was funded by the Norwegian Research Council. The technical assistance of Mrs Kari Andersen, Mr Audun Høylandskjær and Mr Hari Rudra is highly appreciated. We are grateful to Dr Henning Sørum at the Norwegian College of Veterinary Medicine for providing the bacterial strains and to Prof. Loubinoux (Universite de Nancy, France) for the supply of Vetoquinol.

\section{LITERATURE CITED}

Austin B, Rayment J, Alderman DJ (1983) Control of furunculosis by oxolinic acid. Aquaculture 31:101 108

Barnes AC, Lewin CS, Hastings TS, Amyes SGB (1990) In vitro activities of 4 -quinolones against the fish pathogen Aeromonas salmonicida. Antimicrob Agents Chemother $34: 1819-1820$

Blaser J, Stone BB, Groner MC, Zinner SH (1987) Comparative study with enoxacin and netilmicin in a pharmacodynamic model to determine importance of ratio of antibiotic peak concentration to $\mathrm{MIC}$ for bactericidal activity and emergence of resistance. Antimicrob Agents Chemother 31:1054-1060

Elston R, Drum AS, Bunnell PR (1995) Furunculosis injection model for drug efficacy testing of seawater-adapted Atlantic salmon. J Aquat Anim Health 7:16-21

Grave K, Markestad A, Bangen M (1996) Comparison in prescribing-patterns of antibacterial drugs in salmonid farming in Norway during the periods 1980-1988 and 1989-1994. J Vet Pharmacol Therapeut 19:184-191

Inglis V, Richards RH, Varma KJ, Sutherland IH, Brokken ES (1991) Florfenicol in Atlantic salmon, Salmo salar L., parr: tolerance and assessment of efficacy against furunculosis. $J$ Fish Dis 14:343-351

Martinsen B (1993) Quinolones as antimicrobial drugs in aquaculture: antimicrobial activities and pharmacokinetic properties. Dr sci thesis, Norwegian College of Veterinary Medicine, As

Martinsen B, Horsberg TE (1995) Comparative single-dose pharmacokinetics of four quinolones, oxolinic acid, flumequine, sarafloxacin and enrofloxacin in Atlantic salmon (Salmo salar) held in seawater at $10^{\circ} \mathrm{C}$. Antimicrob Agents Chemother 39:1059-1062

Martinsen B, Oppegaard H, Wichstrom R, Myhr R (1992) Temperature-dependent in vitro antimicrobial activity of four 4-quinolones and oxytetracycline against bacteria pathogenic to fish. Antimicrob Agents Chemother 36: $1738-1743$

Michel C, Gerard JP, Fourbet B, Collas R, Chevalier R (1980) Emploi de la flumequine contre la furunculose des salmonides: essais therapeutiques et perspectives pratiques. Bull Fr Piscic 277:154-162

Nordmo $R$, Holth Riseth $J M$, Varma KJ, Sutherland IH, Brokken ES (1998) Evaluation of florfenicol in Atlantic salmon. Salmo salar L.: efficacy against furunculosis due to Aeromonas salmonicida and cold water vibriosis due to Vibrio salmonicida. J Fish Dis 21:289-297

O'Grady P, Moloney M, Smith PR (1988) Bath administration of the quinolone antibiotic flumequine to brown trout Salmo trutta and Atlantic salmon Salmo salar. Dis Aquat Org 4:27-33

Oppegaard H, Sørum H. (1994) Gyra mutations in quinoloneresistant isolates of the fish pathogen Aeromonas salmonicida. Antimicrob Agents Chemother 38:2460-2464

Rodgers CJ, Austin B (1983) Oxolinic acid for control of enteric redmouth disease in rainbow trout. Vet Rec 112:83

Rogstad A, Ellingsen OF, Syvertsen C (1993) Pharmacokinetics and bioavailability of flumequine and oxolinic acid after various routes of administration to Atlantic salmon in seawater. Aquaculture 110:207-220 
Samuelsen OB, Lunestad BT (1996) Bath treatment, an alternative method for the administration of the quinolones flumequine and oxolinic acid to halibut Hippoglossus hippoglossus, and the in vitro antibacterial activity of the drugs against some Vibrio sp. Dis Aquat Org 27: $13-18$

Samuelsen OB, Hjeltnes B, Glette J (1997) Efficacy of orally administered florfenicol in the treatment of furunculosis in Atlantic salmon. J Aquat Anim Health 10:56-61

Scallan A, Smith PR (1985) Control of asymptomatic carriage of Aeromonas salmonicida in Atlantic salmon smolts with flumequine. In: Ellis AE (ed) Fish and shellfish pathology. Academic Press, London, p 119-127

Smith P, Hiney M, Samuelsen OB (1994) Bacterial resistance to antimicrobial agents used in fish farming; a critical eval-

Editorial responsibility: David Bruno,

Aberdeen, Scotland, UK uation on method and meaning. Annu Rev Fish Dis 4: $273-313$

Stamm JM (1989) In vitro resistance by fish pathogens to aquacultural antibacterials, including the quinolones difloxacin (A-56619) and sarafloxacin (A-56620). J Aquat Anim Health 1:135-141

Tsoumas A, Alderman DJ, Rodgers CJ (1989) Aeromonas salmonicida: development of resistance to 4-quinolone antibacterials. J Fish Dis 12:493-507

Washington JA II (1985) Susceptibility tests: agar dilution. In: Lennette EH, Balows A, Hausler WJ Jr, Shadomy HJ (eds) Manual of clinical microbiology, 4th edn. American Society for Microbiology, Washington, DC, p 967-971.

Wolfson JS, Hooper DC (1989) Fluoroquinolone antimicrobial agents. Clin Microbiol Rev 2(4):378-424

Submitted: December 23, 1998; Accepted: March 19, 1999 Proofs received from author(s): June 6, 1999 